\title{
Seismic qualification by analysis of a nuclear class horizontal pressure vessel
}

\author{
Liviu-Constantin $\operatorname{Stan}^{1, *}$, Ioan Călimănescu ${ }^{2}$ and Catalin Faitar ${ }^{1}$ \\ ${ }^{1}$ Constanta Maritime University, Faculty of Naval Electromechanics, Department Electromechanics, \\ 104 Mircea cel Batran Street, 900663 Constanta, Romania \\ ${ }^{2}$ Nuclear Power Plant Cernavoda-Romania
}

\begin{abstract}
The seismic qualification for the structural strength it is an issue for the assessment of the seismic safety of the Nuclear Power Plants. The qualification for seismic events in nuclear industry [4] includes the assessment of the structural integrity and fitness for operability during and after an earthquake. Such qualifications are done for various safety and non-safety equipment among which the pressure vessels are of a paramount importance. The seismic qualification is done either directly on prototypes or scaled prototypes (mock ups) or via analytical methods like analysis with finite elements. In any case the model should accurately represent the actual performance of the component or structure when it is subjected to the prescribed effects. The goal of this article is to underline the procedure to be followed for nuclear industry horizontal pressure vessels in order to obtain sound and credible results for equipment seismic qualification by using the unique analysis features of ANSYS 19. A seismic qualification analysis is carried out for the horizontal pressure vessel. The seismic event is overloading the anchoring system beyond the ultimate strength of the material. The zone where these big stresses fields are calculated is at the anchors level. The vessel as designed failed to be qualified for the seism excitations imposed to the model. In order to have the vessel qualified the anchoring way should be redesigned. By comparing the overall calculated equivalent stresses with the tensile yield strength we may pull the conclusion that the original structure design will fail. Instead the new redesigned anchoring system with 8 extra-anchors will stand.
\end{abstract}

\footnotetext{
* Corresponding author: liviustan14@yahoo.com
} 


\section{Introduction}

The seismic qualification for the structural strength it is an issue for the assessment of the seismic safety of the Nuclear Power Plants.

The qualification for seismic events in nuclear industry [4] includes the assessment of the structural integrity and fitness for operability during and after an earthquake. Such qualifications are done for various safety and non-safety equipment among which the pressure vessels are of a paramount importance.

The seismic qualification is done either directly on prototypes or scaled prototypes (mock ups) or via analytical methods like analysis with finite elements. In any case the model should accurately represent the actual performance of the component or structure when it is subjected to the prescribed effects.

Seismic qualification by analysis should be used for items without a functional safety requirement that are unique or that are of a size or scale to preclude their qualification by testing. Civil engineering structures, tanks, pressure vessels, distribution systems and large items of equipment are usually qualified by analytical methods[5].

In some countries the nuclear class horizontal cylindrical vessels resistant to temperature and internal pressure are designed according to ASME Section III design code, which often result in pressure vessels with wall thicknesses calculated for all the loading scenarios including the seismic one, are governed by the calculation of circumferential stress[6].

But their supports do not always are checked for seismic loads during their design, especially the anchoring system. In seismic response of a structure such a pressure vessel, the saddle supports and the anchoring system to the floor, is mandatory to be checked for resistance when it is called for seismic qualification[7,8].

For numerical analysis the latest advances in simulation technology of ANSYS 19 will be deployed. The main module to be used will be the Response Spectrum meant to perform calculations over the maximum response of a structure when subjected to a transient load (variable in time). The maximum response can be computed as the mode shape times a certain scale factor [1]. Multiple maximum responses then may be combined to give the total response of the vessel. This is an alternative to the more cumbersome full time history.

By knowing the natural frequencies and the mode shapes of the vessel we can simply determine what the displacement would be for a 1-DOF oscillator, if it were subjected to the same transient loading, and scale the response by the appropriate amount. If there is more than one load, in our case one for any direction $\mathrm{X}, \mathrm{Y}, \mathrm{Z}$, each will have its own spectrum. A modal analysis must first be completed to determine the natural frequencies, mode shapes, and participation factors for each mode. For each natural frequency, the spectrum value can be determined by a simple look-up from the response-spectrum table. The mode coefficients can be determined from the participation factors, depending on the type of spectrum input. Participation factors measure the amount of mass moving in each direction for a unit displacement. The response (displacement, velocity or acceleration) for each mode can then be computed from the frequency, mode coefficient, and mode shape. Finally the mode combinations are computed ant they take the form:

$$
[R]=\left(\sum_{i=1}^{n} \sum_{j=1}^{n} \epsilon_{i j}[R]_{i}[R]_{j}\right)^{1 / 2}
$$


where $[R]$ is the total modal response and $[R]_{i}[R]_{j}$ is the product of modes $i$ and $j$. The modal correlation coefficients $\epsilon_{i j}$, are uniquely defined, depending on the method chosen for evaluating the correlation coefficient.

The goal of this article is to underline the procedure to be followed for a nuclear industry horizontal pressure vessel in order to obtain sound and credible results for equipment seismic qualification by using the unique analysis features of ANSYS 19. A seismic qualification analysis is carried out for the horizontal pressure vessel as shown in the Figure 1.

\section{Materials and methods}

The solving strategy is following a series of fixed stages in order to have the right results.

Firstly the CAD geometry of the vessel will be generated by using SpaceClaim as seen in Figure 1:

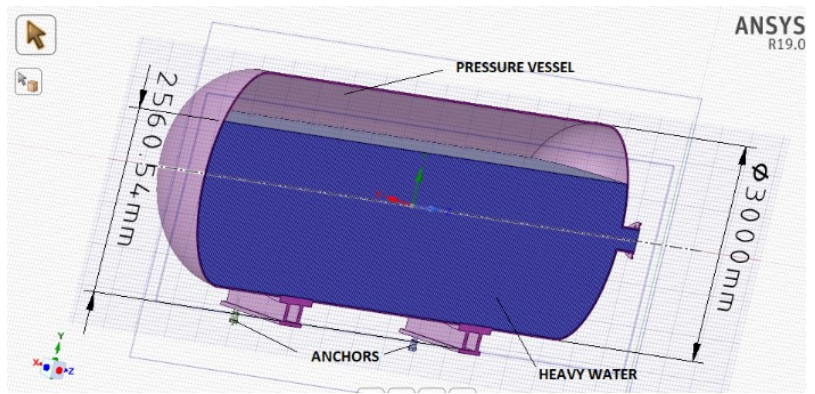

Fig.1. The CAD geometry of the pressure vessel on subject

The geometry is somehow simplified targeting only the major structural features and neglecting small details as instrumentation or name plates. The external diameter of the vessel is $3000 \mathrm{~mm}$ and its length is about $7500 \mathrm{~mm}$. It is sitting on the floor on two saddles fixed via M56 anchors in concrete. The material of the vessel is stainless steel and the stored fluid is radioactive heavy water. The thickness of the vessel wall is $20 \mathrm{~mm}$.

The material imposed is the stainless steel with density of $29,314 \mathrm{~kg} / \mathrm{m}^{3}$, Young modulus of $1.93 \mathrm{e} 11 \mathrm{~Pa}$, Poisson ratio of 0.31 , tensile yield strength of $2.07 \mathrm{e} 8 \mathrm{~Pa}$ and the ultimate strength of $5.86 \mathrm{e} 8 \mathrm{~Pa}$.

The normal density of the stainless steel material is $7750 \mathrm{~kg} / \mathrm{m}^{3}$. But inside the material definition the density has the value of $29,314 \mathrm{~kg} / \mathrm{m}^{3}$. The explanation of this paradox is in the follows.

The basic idea is that we need the mechanical dynamic system of the empty vessel to account for the participation of the heavy water inside. The simplest way is to modify the density of the steel material in order to consider the effects of the water mass and the difference between the centres of mass of the empty vessel and the filled one. For the seismic qualification the vessel is considered partially filled with heavy water as seen in Figure 1. No sloshing effect is considered, the effects of such a phenomenon are negligible in comparison with the seismic effects.

Firstly we will consider the masses of the vessel empty and of the contained water. The volume of the steel for the vessel is $2.2 \mathrm{~m}^{3}$ and the volume of contained water is $41.06 \mathrm{~m}^{3}$. Taking into account the densities of the steel and the heavy water the mass of the steel is $17,050 \mathrm{~kg}$ and the mass of the water is $41,142 \mathrm{~kg}$. The total mass is $58,192 \mathrm{~kg}$. By dividing the total mass to the steel volume the new density of the steel to mimic the mass of water should be $26,450 \mathrm{~kg} / \mathrm{m}^{3}$. 
Secondly (see Figure 2) let's analyse the position of centre of mass for the empty vessel and the vessel filled with heavy water. The empty vessel has the coordinates of the mass centre $(-4.65,-411.7,13.29) \mathrm{mm}$ and the filled one $(-4.85,-253.26,2.99) \mathrm{mm}$. Knowing that the distance from the saddle to vessel axis is $1870 \mathrm{~mm}$ then the overturn moment arm of the empty vessel is $1459 \mathrm{~mm}$ and of the filled vessel is $1617 \mathrm{~mm}$ (in the Oy direction-the vertical direction). We need to have an equal overturn moment and since the acting forces are proportional to the masses which are proportional to the densities, the final steel density is given by the equation $(26,450 \times 1617) / 1459=29,314 \mathrm{~kg} / \mathrm{m}^{3}$. This new density for the steel is not affecting the mechanical properties of the system but is mimicking the presence of the water inside the vessel. Thus the new mechanical dynamic model is a good approximation of the real model.
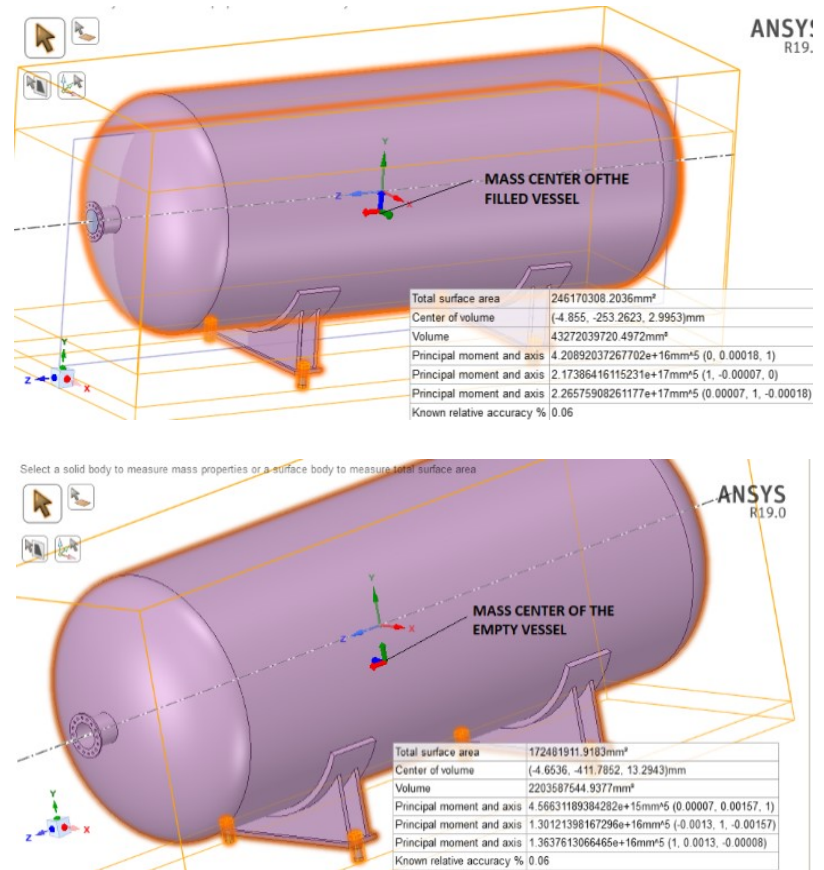

Fig.2. The centres of masses for the filled and the empty vessel

The connections are left bonded type as default and the finite elements mesh is shown in the Figure 3:

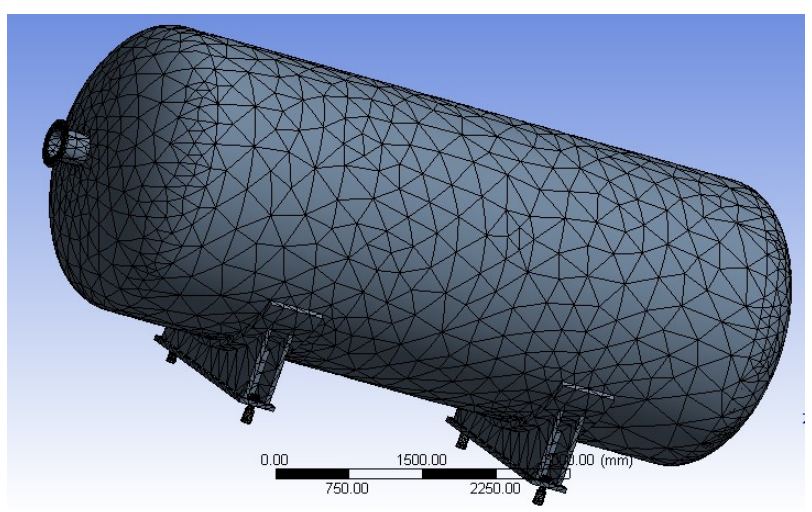


Fig.3. The finite elements mesh

There will be 20995 finite elements with 40709 nodes with an acceptable element quality.

There will be some boundary conditions to be imposed for the model.

For the static structural module the loads are as seen in the Figure 4.

The four anchors transmitting the load from the vessel to the floor will be set as fixed supports. Thru the same fixed supports the seismic excitation will be imposed from the building to the vessel.

The standard earth gravity will be imposed for the entire model and is placed in the centre of gravity of the structure. It is acting in the negative Oy direction of the model.

The contact surfaces between the saddles and the floor are modelled as compression only supports. A $0.3 \mathrm{MPa}$ pressure of the fluid is imposed on the inner surfaces of the vessel. The large deflection is on and the solver to be used is the direct one.

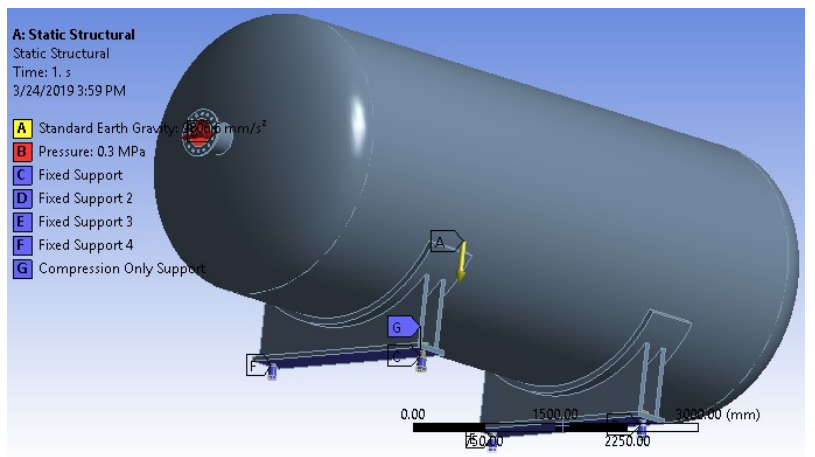

Fig.4. The boundary conditions

Once the deformations and the stresses are calculated inside the structural module, these results are imported inside the modal module in order to calculate the natural frequencies and the mode shapes. The natural frequencies will be calculated only for $0-33 \mathrm{~Hz}$ interval that is meaningful in the seismic assessment for the nuclear industry. The value of $33 \mathrm{~Hz}$ is known as the cut-off frequency as well.

The modal shapes will be furthermore used inside the Response spectrum modules for calculating the loaded structure response to any seismic excitation coming for any of the three directions. Therefore the response spectrums are to be defined for the three directions. These response spectrums are defined for any building and any elevation from the design stage of the plant and they are well known. They are given in g's meaning multiples of the gravitational acceleration of the floor. Therefore a scale factor of $9.81 \mathrm{~m} / \mathrm{s}^{2}$ will be imposed once the values are tabulated.

For Ox axis of the vessel which is horizontally perpendicular on the axis the graph is looking as in Figure 5:

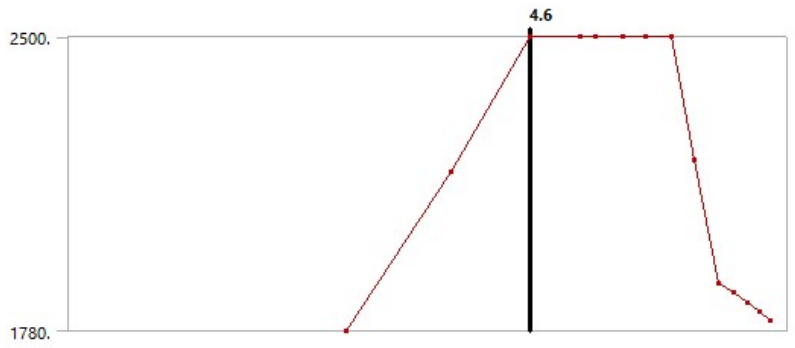

Fig.5. Response spectrum for Ox direction 
For $\mathrm{Oz}$ axis of the vessel which is horizontally parallel to axis the graph is looking as in Figure 6:

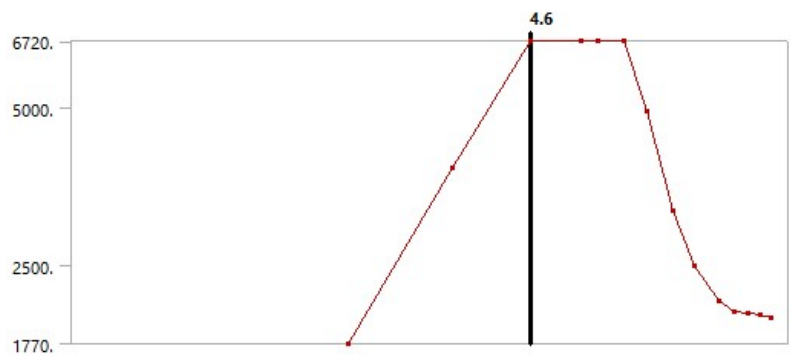

Fig.6. Response spectrum for $\mathrm{Oz}$ direction

For Oy axis of the vessel which is vertically perpendicular to the axis the graph is looking as in Figure 7:

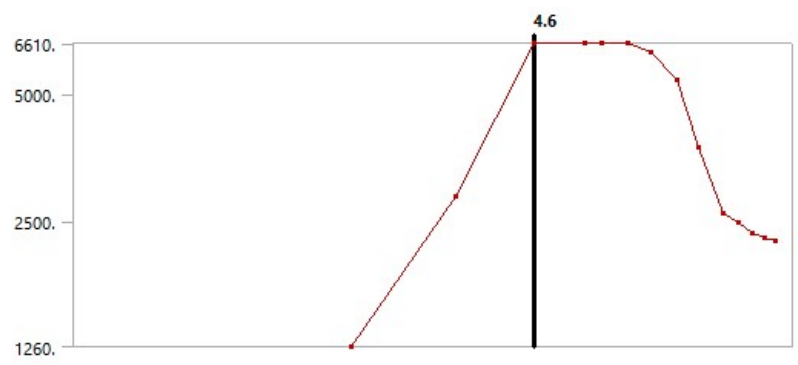

Fig.7. Response spectrum for Oy direction

Care should be taken in response spectrum definition since the crane might be placed in between elevations thus a linear interpolation of the values should be acceptable. Furthermore the Regulatory for nuclear industry in most of the countries and following the Fukushima accident requested for increasing of these values with a certain amount, usually $0.4 \mathrm{~g}$.

All these modules will calculate the total deformations and stresses for the structure in three different directions. In order to combine these results between themselves and with the structural results a last module will be used: the Design assessment one. This module will combine all the above calculated results in one overall result.

\section{Results and discussion}

\subsection{The structural module results}

After running the model some important results were retrieved in the structural model. The total deformations are shown in the Figure 8. Since the loads are acting in the vertical direction the middle section of the vessel will deform in this direction with an amount of $0.62 \mathrm{~mm}$. This is in accordance with any simple engineering educated guess. 


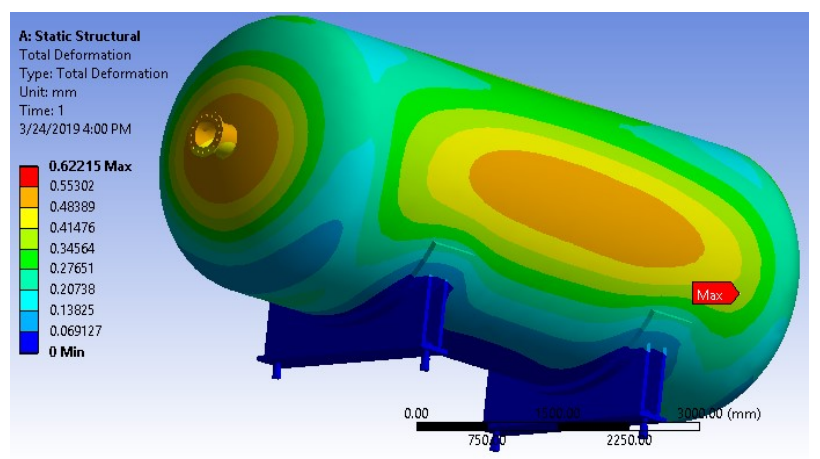

Fig.8. The total deformation calculated with the structural module

In the Figure 9 the von Mises equivalent stress is shown.

The maximum pressure of 3 bar and the weight of the structure is developing mild stresses inside the structure. The maximum stress of $44 \mathrm{MPa}$ is calculated for the nozzle neck.

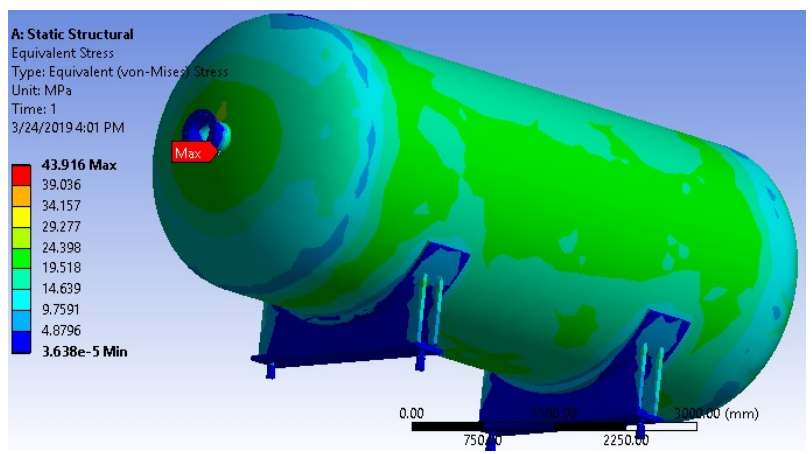

Fig.9. The equivalent stresses calculated with the structural module

\subsection{The Modal Module}

This modal module is calculating the mode shapes and natural frequencies for the loaded structure in the interval $0-33 \mathrm{~Hz}$ of interest. Actually four frequencies were calculated for $10.4,23.2,24.4$ and $27.1 \mathrm{~Hz}$. For the first frequency the total deformation is given in the Figure 10:

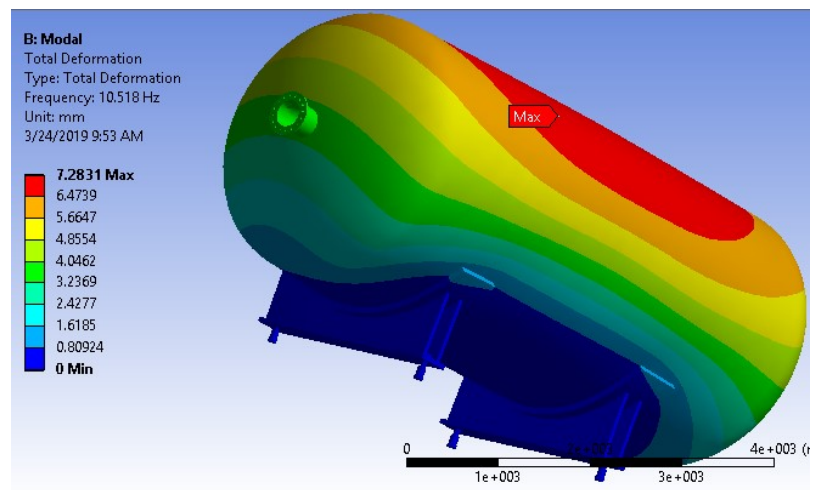

Fig.10. The total deformation calculated in modal module 
The first mode shape is perpendicular to the axis in the vertical direction.

The mass participation factors for the first natural frequency of $10.4 \mathrm{~Hz}$ are given in Table 1:

Table 1 Participation factors

\begin{tabular}{|c|c|c|}
\hline DIRECTION & $\begin{array}{c}\text { PARTIC. } \\
\text { FACTOR }\end{array}$ & $\begin{array}{c}\text { RATIO EFF. } \\
\text { MASS TO } \\
\text { TOTAL MASS }\end{array}$ \\
\hline $\mathrm{X}$ & 5.72 & 0.49 \\
\hline $\mathrm{Y}$ & 0.04 & $0.25 \mathrm{e}-4$ \\
\hline $\mathrm{Z}$ & -0.03 & $0.17 \mathrm{e}-4$ \\
\hline ROTX & 7.92 & $0.16 \mathrm{e}-6$ \\
\hline ROTY & 23.8 & $0.15 \mathrm{e}-5$ \\
\hline ROTZ & -4921 & 0.16 \\
\hline
\end{tabular}

By analysing the participation factors one might the conclusion that the crane is very prone to rotate over $\mathrm{Oz}$ which is the vessel axis.

\subsection{The Response Spectrum module}

\section{- Ox direction}

In this direction the earthquake excitation will make the vessel to deform as seen in Figure 11 below.

The seismic excitation is imposing a rather big deformation of $7.5 \mathrm{~mm}$. The maximum calculated equivalent stresses are big as well as in Figure 12. The maximum stress is on one of the anchors and it is $310 \mathrm{MPa}$. Even at this stage we may pull the conclusion that the seismic qualification of the vessel failed.

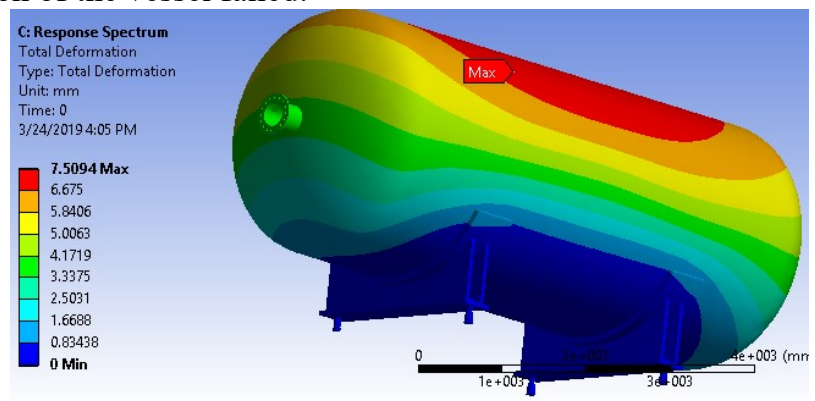

Fig.11. Total deformation for Ox excitation

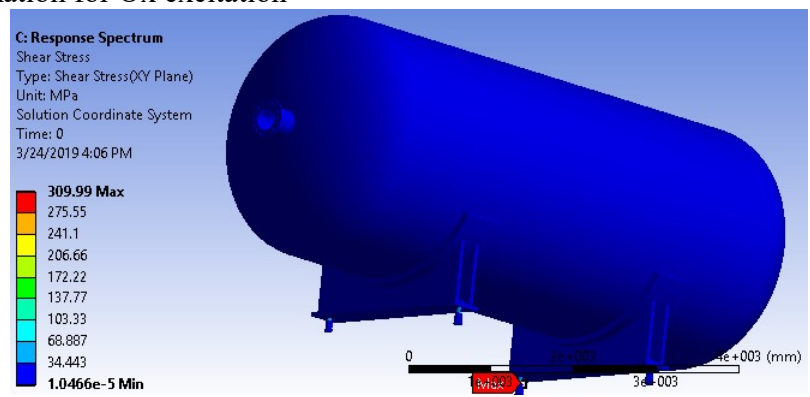

Fig.12. Equivalent stress for Ox excitation

\section{- Oz direction}




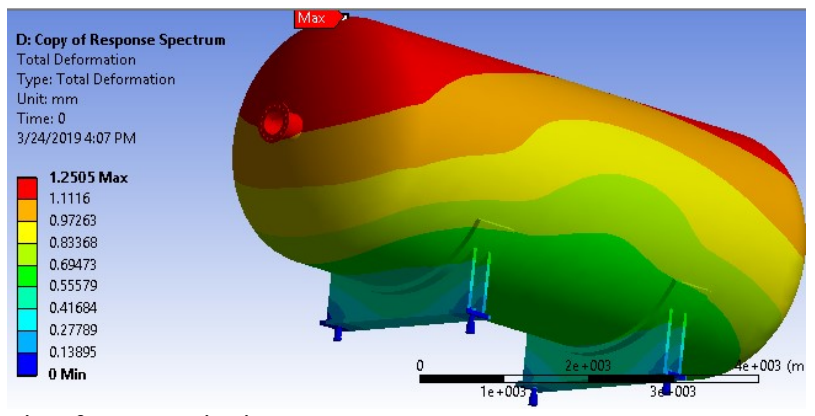

Fig.13. Total deformation for $\mathrm{Oz}$ excitation

The seismic excitation is imposing a relatively small deformation on the structure no more than $1.25 \mathrm{~mm}$. The stresses are rather big on the anchor level, $561 \mathrm{MPa}$, as in Figure 14:

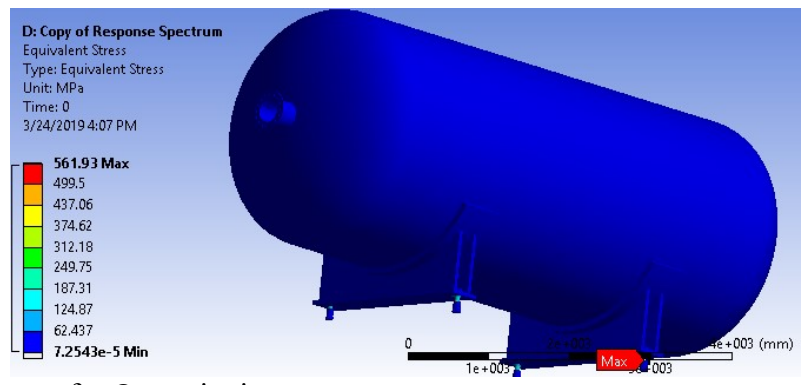

Fig.14. Equivalent stress for $\mathrm{Oz}$ excitation

\section{- Oy direction}

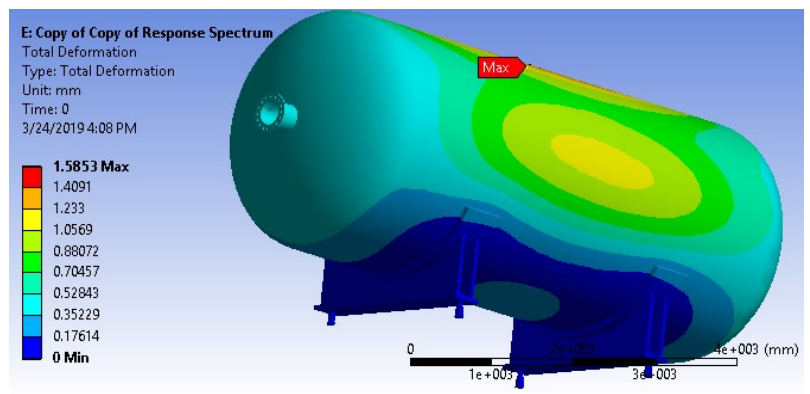

Fig.15. Total deformation for Oy excitation

The seismic excitation is imposing a small deformation on the structure no more than $1.58 \mathrm{~mm}$. 


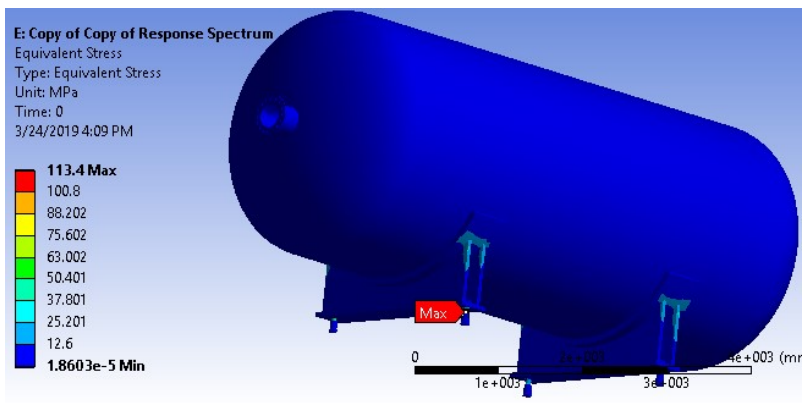

Fig.16. Equivalent stress for Oy excitation

The stresses developed in Oy direction are big with a maximum of $113 \mathrm{MPa}$ somewhere on anchors (Figure 16).

\subsection{The Design assessment module}

This last module is taking all the results from Structural and response spectrum modules and is consolidating everything into one single structure state by combining them.

Regarding the total deformation the calculated overall result is given in Figure 17:

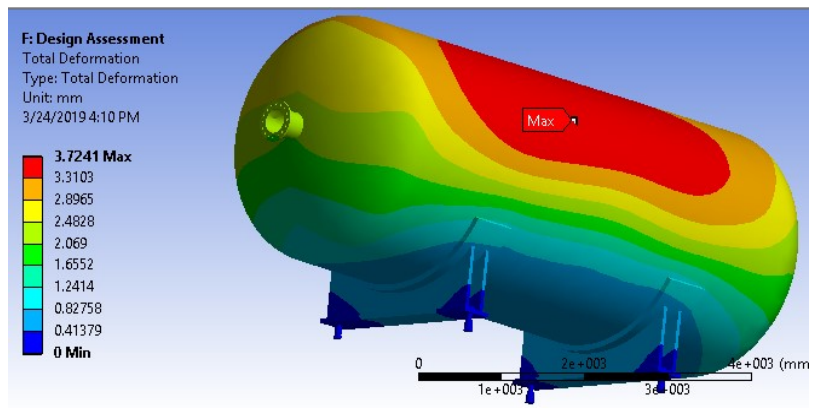

Fig.17. The overall total deformation

The overall total deformation is showing that the vessel structure suffers a bending and rotation over $\mathrm{Oz}$ axis yet the value rather big, $3.6 \mathrm{~mm}$ deformation is recorded for the upper side vessel.

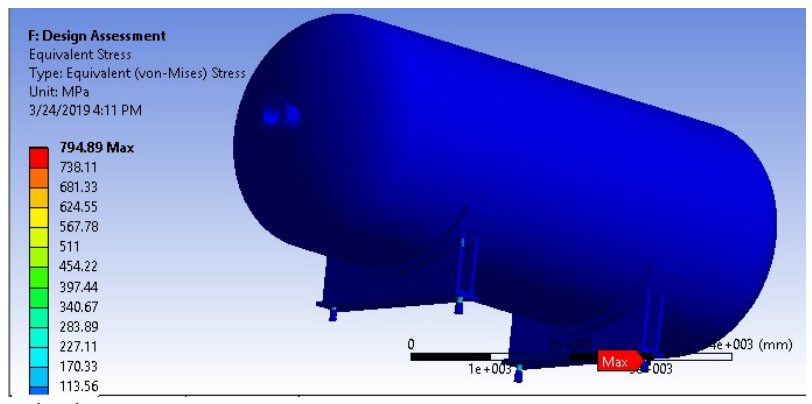

Fig.18. The overall equivalent stress

The overall stress in Figure 18 shows that the peak stress of $794 \mathrm{MPa}$ calculated is bigger than the ultimate strength of the stainless steel material of $586 \mathrm{MPa}$. This means the anchors are breaking following a seismic event. 
The procedure above is adding algebraically with the rule of 100-40-40 the maximum responses and is allowed by US NRC Regulatory Guide 1.92. It is an alternative for SRSS method of combining the results. That is the bigger result in the Oz direction is taken $100 \%$ and the other 2 in Oy and Ox direction are taken in the algebraic addition as 40\%. As per US NRC Regulatory Guide 1.92 [3]:

"The 100-40-40 percent rule was originally proposed as a simple way to estimate the maximum expected response of a structure subject to three-directional seismic loading for response spectrum analysis, and is the only alternative method for spatial combination which may be used. The results of the 100-40-40 spatial combination have been compared with the SRSS spatial combination. Generally, they indicate that the 100-40-40 combination method produces higher estimates of maximum response than the SRSS combination method by as much as 16 percent, while the maximum under-prediction is 1 percent."

\subsection{Anchoring system redesigned}

Since the performance of the anchoring system of the vessel seems to render unsatisfactory results, the system was redesigned by adding other 8 anchors as in the Figure 19:

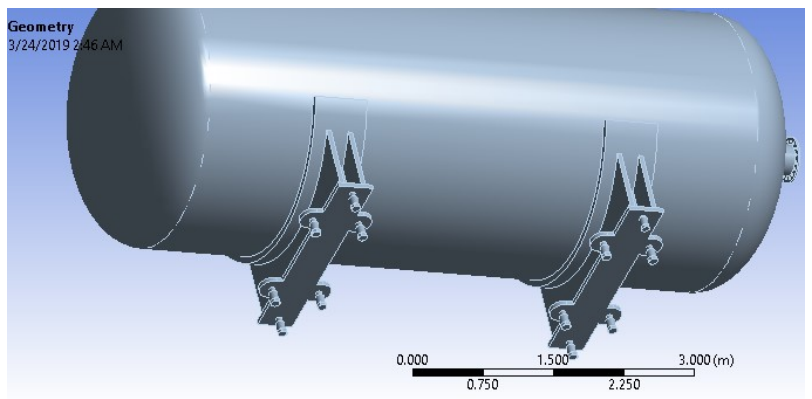

Fig.19. The anchoring system redesigned

The new model was solved by going through all the stages described above and the overall equivalent stress is shown in the Figure 20.

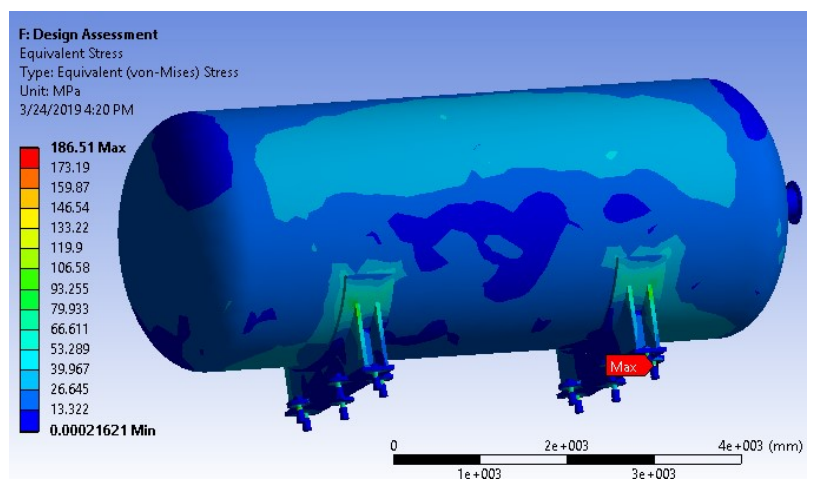

Fig.20. The overall equivalent stress for the anchoring system redesigned

The maximum stress is now recorded for a single stud and has the value of $186 \mathrm{MPa}$ which is lower than the yield strength of 207 MPA. The safety factor is 1.11 . 


\section{Conclusions}

This study is meant to show how a complex structure as a pressure vessel might be treated in order to have meaningful results for a decision whether or not such a structure is able to withstand the loads generated by a seismic event.

The seismic event is overloading the anchoring system beyond the ultimate strength of the material. The zone where these big stresses fields are calculated is at the anchors level. The vessel as designed failed to be qualified for the seism excitations given above. In order to have the vessel qualified the anchoring system should be redesigned.

By comparing the overall calculated equivalent stresses with the tensile yield strength, we may pull the conclusion that the original structure design will fail. Instead, the new redesigned anchoring system with 8 extra-anchors will stand.

\section{References}

1. ANSYS 19 documentation

2. Seismic Design Classification, Regulatory Guide 1.29, U.S. Nuclear Regulatory Commission, (2007).

3. US NRC Regulatory Guide 1.92, Combining Modal Responses and Spatial Components in Seismic Response Analysis, Rev.2, (2006).

4. Safety Standards Series No.NS-G-1.6, Seismic Design and Qualification for Nuclear Power Plants Safety Guide

5. EPRI, Recommended Piping Seismic Adequacy Criteria Based on Performance During and after Earthquakes, Report NP-5617, January 1988

6. US NUCLEAR REGULATORY COMMISSION, Seismic fragility test of a 6-inch diameter pipe system, NUREG/CR-4859 (1988)

7. SEISMIC QUALIFICATION UTILITY GROUP (SQUG), Generic Implementation Procedure (GIP) for Seismic Verification of Nuclear Plant Equipment, February 1992

8. EPRI, NP-7500-SL, The October 17, 1989 Loma Prieta Earthquake: Effects on selected power and industrial facilities, September 1991 